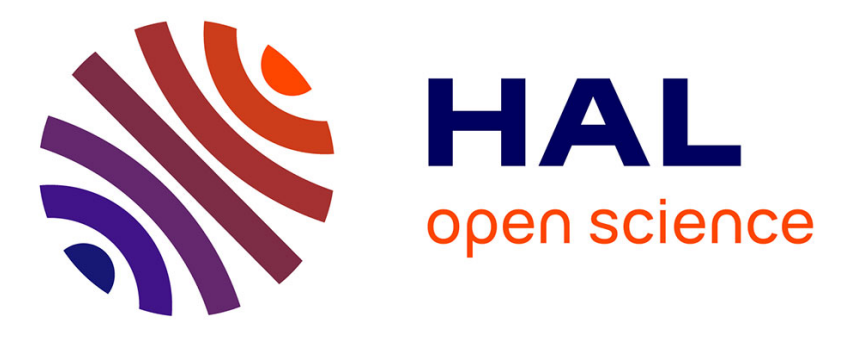

\title{
Understanding Process Quality in the Context of Collaborative Business Network Structures
} Patrick Sitek, Novica Zarvić, Marcus Seifert, Klaus-Dieter Thoben

\section{To cite this version:}

Patrick Sitek, Novica Zarvić, Marcus Seifert, Klaus-Dieter Thoben. Understanding Process Quality in the Context of Collaborative Business Network Structures. International Conference on Advances in Production and Management Systems (APMS), Sep 2009, Paris, France. pp.545-552, 10.1007/9783-642-16358-6_68. hal-01055811

\section{HAL Id: hal-01055811 \\ https://hal.inria.fr/hal-01055811}

Submitted on 13 Aug 2014

HAL is a multi-disciplinary open access archive for the deposit and dissemination of scientific research documents, whether they are published or not. The documents may come from teaching and research institutions in France or abroad, or from public or private research centers.
L'archive ouverte pluridisciplinaire HAL, est destinée au dépôt et à la diffusion de documents scientifiques de niveau recherche, publiés ou non, émanant des établissements d'enseignement et de recherche français ou étrangers, des laboratoires publics ou privés.

\section{(c)(1)}

Distributed under a Creative Commons Attribution| 4.0 International License 


\title{
Understanding process quality in the context of collaborative business network structures
}

\author{
Patrick Sitek $^{1}$, Novica Zarvic ${ }^{2}$, Marcus Seifert ${ }^{1}$, Klaus-Dieter Thoben ${ }^{1}$ \\ ${ }^{1}$ BIBA Bremer Institut für Produktion und Logistik GmbH, Hochschulring 20, \\ 28359 Bremen, Germany \\ \{sit, sf, tho\}@biba.uni-bremen.de \\ ${ }^{2}$ Universität Osnabrück, Informationsmanagement und Wirtschaftsinformatik, \\ Katharinenstr. 3, 49069 Osnabrück, Germany \\ novica.zarvic@uni-osnabrueck.de
}

\begin{abstract}
Demanding customer requirements have led to the situation where products are realised in collaborative business networks by different cooperating companies. In an extreme case such networks exist only for one specific customer order. Such temporary and dynamic organisation forms make new demands on Quality Management (QM) approaches. Existing QM practices mostly focus on assuring and improving quality of standardised processes inside single companies or long-term relations between business partners in supply chains. This paper discusses in particular the exchange of quality-relevant information flows and processes in the different constellations of collaborative business networks that are conceivable in real life.
\end{abstract}

Keywords: Quality Management, Process Quality, Collaborative Business Network Structures, Core Competencies.

\section{Introduction}

Global competition, highly dynamic markets, reduced investment capability, and many other external influences exert great pressure on manufacturing companies to react, change and adapt proactively to the environment. Customers expect personalised, complex and "end-to-end" solutions made of customised products complemented by related after-sales services. A major trend is related to the fact that no individual company is able to be competitive and develop or provide alone the whole spectrum of products, as well as services around these products, to satisfy today's customer demands and needs. To face these challenges companies have to become more flexible, adaptable, in order to easily find other companies and integrate them for working in collaborative business networks. This requires not only the capability for enterprises (and SMEs in particular) to identify, model and expose their core competencies, but the capability to run their business processes in highly dynamic, short-time and often not-hierarchical business environments. 
In general business networks are defined by nodes (network members) and relationships between these nodes [21]. Real life networks can be seen more or less as complex combinations of various types of bilateral relationships between those nodes. The multitude of conceivable business network constellations makes it therefore a necessity to look in more detail at the commonalities of these constellations, in order to be able to define general valid claims with respect to the flows of quality-relevant information. The extraction of properties common to all conceivable networks contributes therefore to the body of principles relevant in QM, because it allows us to discuss process quality in the context of any conceivable cooperation form.

The paper is organised as follows: section 2 provides background information and a scientific discussion on business network forms. Section 3 discusses process quality in an inter-organisational context and brings it into relation with the previously discussed inter-organisational structures. In section 4 we discuss new directions on process quality from an inter-organisational perspective. The presented idea contributes to second the need for the further development of existing approaches to competence management in order to support QM by modeling of communication structures in business networks. Finally, section 5 concludes the paper.

\section{On collaborative business network structures}

\subsection{Collaboration types}

Several classification approaches of inter-organisational collaboration types are conceivable. For instance, classifications of the participating business actors e.g. according to the branches they are operating in or even according to the geographical application areas can be performed. However, these examples do not consider deep enough the previously mentioned concepts by Thoben and Jagdev [21], namely nodes and edges that make up a collaboration structure.

In the field of organisation theory, Thompson [22] investigated how relationships between organisational tasks influence the structure of an organization [7] and discussed three forms of interdependencies that can arise between working units. He distinguished sequential interdependency, pooled interdependency and reciprocal interdependency. These interdependencies are building the basis for the interorganisational system (IOS) typology that was later created by Kumar and van Dissel [9]. The nodes in their typology represent (business) systems and the edges indicate on interdependencies between the nodes. In the following we look more detailed at three IOS types, which are the value/supply chain IOS, the pooled information resource IOS, and the networked IOS. The first type, value/supply chain IOS supports the relationships between customers and suppliers that appear sequentially. Thus, it represents sequential interdependency between companies. This type is represented by Kumar and van Dissel as a directed graph, where the arrows between the nodes go sequence-wise from left to right. The next type, pooled information resource IOS, is representing an inter-organisational sharing of common IT resources. Data movement is directed towards a central entity, explaining the direction of the arrows in the graph, which in turn show the interdependence on the central node. The last type networked 
IOS "operationalises and implements reciprocal interdependencies between organizations". This type is also represented as a graph, where each node is connected with all other nodes, and the edges between the nodes have arrows in both directions.

\begin{tabular}{|l|l|l|}
\hline $\begin{array}{l}\text { A. Interdependency type } \\
\text { B. IOS type }\end{array}$ & Graph-based representation & Support type and examples \\
\hline $\begin{array}{l}\text { A. Sequential } \\
\text { interdependency } \\
\text { B. Value/Supply chain IOS }\end{array}$ & $\begin{array}{l}\text { - Support of Porter's value system } \\
\text { concept } \\
\text {-e.g. EDI applications for IT- } \\
\text { enabled supply chains }\end{array}$ \\
\hline $\begin{array}{l}\text { A. Pooled } \\
\text { interdependency } \\
\begin{array}{l}\text { B. Pooled Information } \\
\text { Resource IOS }\end{array}\end{array}$ & $\begin{array}{l}\text { - Marketplaces, shared databases, } \\
\text { central production points } \\
\text {-e.g. support usage of pooled } \\
\text { resource, support of centralized } \\
\text { production points }\end{array}$ \\
\hline $\begin{array}{l}\text { A. Reciprocal } \\
\text { interdependency } \\
\text { B. Networked IOS }\end{array}$ & $\begin{array}{l}\text { - Networks } \\
\text {-e.g. support of n-to-n } \\
\text { communication between all } \\
\text { participants }\end{array}$ \\
\hline
\end{tabular}

Fig. 1. IOS typology (adapted from [9])

\subsection{Graph-theoretical considerations}

The three types of inter-organisational collaboration discussed in the previous subsection represent the possible collaboration structures that can appear. It is clear that we can find inter-organisational business structures that differ much from these three types, so that the question arises whether these three types suffice for explaining all the collaborative business network structures that are omnipresent in real-life. We claim that each conceivable collaborative business network structure can be decomposed into these three types, which means that each business network is either representable by one of these types or by a combination of these types. In the following we provide a graph-theoretical discussion, which proves our claim:

In Fig. 1 three IOS types are considered and represented by means of graphs. Graph-theoretically these are, in the undirected case, paths $P_{n}$, stars $K_{1, n}$ and cliques $K_{n}$. Remember that nodes and relationships between them are defining business networks as stated by Thoben and Jagdev [21]. Therefore we can consider here undirected graphs, because the pure existence of an edge suffices for representing a relationship between nodes. The reader may wonder whether the number of types discussed in this paper is not too restrictive for representing all conceivable collaboration structures. Therefore we need to consider another basic structure, which is the bipartite graph, where two sets of $n_{l}$, respectively $n_{2}$ nodes are considered, and edges only connect two nodes from different sets. The star $K_{l, n}$ is a special case of a bipartite graph. Now, we consider an arbitrary connected graph $G$, representing a collaboration structure. Suppose we have determined all cliques in $G$ of order greater than 2 . We then remove all the edges in these cliques, which gives a graph $G^{*}$ without cliques of order greater than or equal to $3 . G^{*}$ needs not be connected anymore. Now 
consider these nodes in $G^{*}$ that have degree greater than 2. These are central nodes of stars. We now remove the edges of these stars to obtain a graph $G^{* *}$. Graph $G^{* *}$ has only nodes of degree 0,1 , or 2 and therefore consists of single nodes, single edges and paths. The conclusion of this decomposition procedure is that the three types of IOS forms indeed suffice to describe any collaboration structure or communication structure in collaborative business networks respectively as will be explained in the next subsection.

\subsection{Summary and conclusions}

In this section it was shown that the three discussed collaboration types suffice for representing any conceivable collaboration structure. Further, they build a suitable basis for discussing communication in business networks, because for each collaboration structure there exists another type of interdependence. For managing such an interdependence, thus for enabling the collaboration, information exchange is at least conditionally needed between the nodes, which in turn also implies the aspect of exchange of quality-relevant information. Relevant information flows, including those which affect process-quality, can only take place along the collaboration structure of a business network, because collaboration presupposes a certain degree of communication and information exchange. With relevant we mean information that contributes to the fulfillment of the end customers' requirements on the product itself. Considering only product structure logic might not suffice, because information exchange to guarantee process-quality can depend on the collaboration type.

Another asset of considering the collaborative business network structure is given by the fact that by considering the degree of a node, we can beforehand determine the number of business actors one actor will collaborate and hence communicate with, which is very helpful for developing the inter-organisational workflow as well as to determine the number of partners one company has to communicate with in a network as can be seen from Table 1 .

Table 1. Bilateral vs. multilateral relations in collaborative business network structures.

\begin{tabular}{|c|c|c|c|c|c|c|c|c|c|c|c|c|c|c|c|}
\hline & \multicolumn{5}{|c|}{ Sequential } & \multicolumn{5}{|l|}{ Pooled } & \multicolumn{5}{|c|}{ Reciprocal } \\
\hline & $\mathbf{A}$ & B & C & D & $\mathbf{E}$ & F $\quad \mathbf{G}$ & H & I & $\mathbf{J}$ & $\mathbf{K}$ & $\mathbf{L}$ & M & $\mathbf{N}$ & $\mathbf{O}$ & $\mathbf{P}$ \\
\hline $\begin{array}{l}\text { Bilateral } \\
\text { Multilateral }\end{array}$ & $\mathrm{X}$ & $X$ & X & $X$ & X & $\mathrm{X} \quad \mathrm{X}$ & $\mathrm{X}$ & $\mathrm{X}$ & $\mathrm{X}$ & $X$ & $X$ & $X$ & $\mathrm{X}$ & $X$ & $X$ \\
\hline
\end{tabular}

In the sequential collaboration type only the first and last network members are in bilateral relation, which means that they communicate with exactly one other member, whereas all other nodes are in multilateral relation and are communicating with two other network members. In the pooled collaboration type all outer nodes are in bilateral relation to the central node, which has on the other side multilateral relation to all outer nodes. Lastly, the reciprocal collaboration type is characterized by the fact that all member nodes are standing in multilateral relation, indicating that the number of communication channels for each network member is $n-1$. Having this knowledge about communication channels enables us also to reason about the flows of quality-relevant information in a structured way. 


\section{Process quality in a networked business context}

Robinson and Malhotra's [15] intensive literature study published in 2005 of leading journals from the field of Production and Operations Management uncovered that only few studies examine the topics of QM and collaborative enterprise networks in combination. Their study indicates the main finding that product quality is not the only aspect which leads to quality in networks, but the process quality. Therefore a smooth and synchronised linkage between processes (process integration) is critical to an efficient and operative network [16]. Already the movement in long-term networks, like supply chains, embraces process quality management initiatives. The shift from product to process orientation to achieving quality and ultimately customer satisfaction was therefore the premise of the ISO 9001 standard as revised in the year 2000 [6]. Processes in networks can be aligned to different classified collaboration levels. Following [5] there are four different levels:

(1) Level of individual network actors in a company (intra-organisational viewpoint; relations between single persons in different departments)

(2) Level of single domains in a company (intra-organisational viewpoint; relations between departments within an organisation)

(3) Level of inter-organisational relations between companies (interorganisational viewpoint; relations between network members)

(4) Level of institutional contexts (inter-organisational viewpoint; relations between networks)

The definition of quality in this paper follows the guidelines of the Quality Management DIN EN ISO 9001:2000 fundamentals and vocabulary [6]. Thereafter, requirements to a final outcome (e.g. product, service) are communicated from the customer towards an organisation. These requirements are transferred as information into process instructions, which present the way to execute organisational processes to guarantee quality [11]. From the inter-organisational perspective (level 3+4) contributions of each actor might have an impact on the outputs of another actor in the collaborative business networks. This is also explained by the interdependencies discussed in section 2. Such an impact would also have consequences for the internal process instructions of an actor and thus the need to adapt and to diverge from the actor's standard processes. In such a case today's QM would fail due to the lack of information to adapt internal processes (level 1+2) resulting from dependencies caused by the specific constellation of actors (level 3+4) [19].

The challenge is to exchange right information with right content between right actors. Therefore an effective communication structure is indispensable between the actors on the inter-organisational level. Such a communication structure is to understand as a guideline in order to identify and coordinate the information exchange between actors. The aim should be to avoid misunderstandings and a lack of information which could affect process descriptions in a negative way. Such a coordination of information via communication structures cannot be specified in collaborative business networks in general, because the relations between actors and the issues of controlling actors also cannot be generalised and pre-defined as they are situation and case dependent.

Today's business networks manage their communication structures by using product structure logic as an indicator for the inter-organisational exchange of 
information. This is due to the fact that the production function provided by an actor drives the partnership and the acting in the collaborative business networks. As discussed in section 2 , unfortunately a product structure logic that is following a sequential interdependency (see Fig.1) is not sufficient to represent a communication structure in business networks. While using a product structure as communication logic, business networks run the risk not to identify all dependencies between their actors and thus not to exchange all information needed between the actors (Fig. 2).
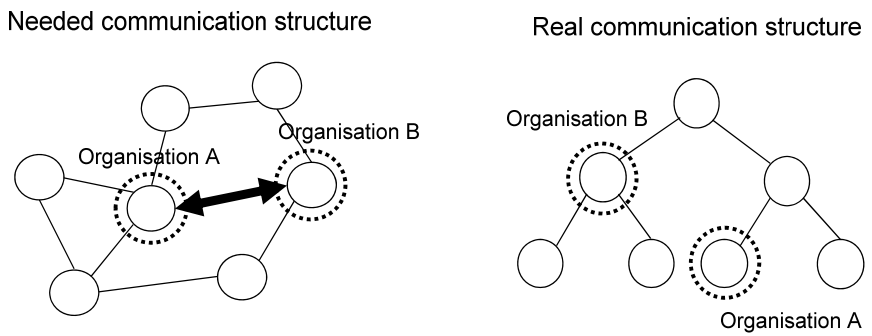

Fig. 2. Needed vs. real communication structure

Product structure logic (e.g. Bill of Material) can only reveal dependencies on the product level, not dependencies caused by the specific constellation of actors in a business network. This is due to the fact that actors contribute not only with a product, but with their core competences. As a matter of fact, for each actor's contribution these inter-organisational dependencies might have an unforeseen impact on defining and communicating the right information to other actors. Consequently they are very critical to quality aspects in satisfying the customer requirements [13].

\section{Linked Competences as Model to define Communication Structures}

Core competence is a significant factor that influences the management and design of an enterprise structure [1]. Prahalad and Hamel [14] introduced the concept of core competences. They define a core competence as "an area of specialised expertise that is the result of harmonising complex streams of technology and work activity". Competence is the main concept for the definition of the competitiveness of a company [12], especially on entering environments like collaborative business networks. Molina and Bremer [12] define the constituent information elements of a competence. The information entities that describe a competence are [4]:

- Product/Service: core product/service of a company, which are attractive from the perspective of the customer and the market, and which could make a substantial contribution to the business network

- Processes (Business Processes): All the core processes that are needed to offer the company's product/service to the business network

- Skills (Technology): Theoretical and practical knowledge, skills and abilities that are used to develop the product/service 
Each actor's unique combination of these entities constitutes its identity as competence. Completed by the business opportunity driven "task" as a part of the information entity of a competence, the competence provides a defined set of data specific to a selected consortium in a business network. Thus, the competence defines the actor's specific role in the network and unique need for information.

In business networks competences are already used to set up actors' profiles and to measure their performance prospectively [17] in order to search for and to select the right actors for a specific business opportunity [18, 4, 17]. But they are not regarded in terms of modeling communication structure. To face the challenge to model communication structures in business networks, the idea is not to follow the product structure logic but the structure of linked competences in a business network. It is well known, by linking competences of actors in business networks, that a temporary value chain will be created $[2,10]$. The logic of linking competences follows the given task dependence that may be seen as the concept of division of work [20]. In a network it is not the division of work between workers but between actors which are specialised units connected in a global network. Actors' processes are ideally allocated to where they are carried out in the most effective way and contributing value to the customer's final product in an integrated global production system [8]. Actors in business networks link, change and exchange resources via processes with other actors. As a result of the task dependence between actors the information to be exchanged by transactions of one actor might affect processes and so the competence of the next actor in the value chain.

\section{Summary and conclusions}

Inter-organisational relations and dependences have a much higher and yet rather unknown influence on the quality delivered by business networks to the final customer. A deeper analysis of the dependences on actor's competences in business networks might be a comprehensive approach to guarantee process quality on interorganisational level. The main goal is to identify, out of these dependences, information that might affects processes between actors in a business network. Additional information exchanged by the help of an inter-organisational communication structure can be used as input information to adapt process instructions on intra-organisational level. Existing QM approaches would then make sure that the output contributed from each actor is conforming to the specifications of the overall business network outcome.

The analysis of dependences between competences deserves further study. The main goal at the end is to provide smart guidelines to model quickly and easily a communication structure based on competences for a specific business network from an inter-organisational perspective. As in any other scientific discipline, network organisations require the development of models to better understand the area [3]. Modelled inter-organisational communication structures could help to guarantee a successful distribution of customer's requirements through the entire value chain of a business network and thus contribute to process quality. 


\section{References}

1. Binder, M., Clegg, B.T.: Enterprise management: a new frontier for organizations. International Journal of Production Economics. Vol. 106, No.2, 406-430 (2007)

2. Camarinha-Matos L.M., Afsarmanesh H.: A framework for virtual organization creation in a breeding Environment. Annual Reviews in Control. Vol. 31, No. 1, 119-135 (2007)

3. Camarinha-Matos L.M., Afsarmanesh H.: A comprehensive modeling framework for collaborative networked organisaztions. J. for Intellect. Manufact., Vol.18, 529-542 (2007)

4. Ermilova, E., Afsarmanesh, H.: Competency and Profiling Management in Virtual Organization Breeding Environments. In Camarinha-Matos, L.M., Afsarmanesh, H. and Ollus, M. (eds.) Network-Centric Collaboration and Supporting Frameworks, IFIP, pp. 131142, Springer, New York (2006)

5. Gilbert, D.U.: Vertrauen in strategischen Unternehmensnetzwerken - ein strukturaktionstheoretischer Ansatz", DUV, Wiesbaden (2003)

6. ISO 9001:2000: Quality management systems - Requirements ICS: 03.120.10 (2000)

7. Jones, G.R., Bouncken, R.B.: Organisation, Theorie, Design und Wandel, 5th edit. Pearson Studium Verlag (2008)

8. Karlsson, C.: The development of industrial networks: challenges to operations management in an extraprise. Int. J. of Operat. \& Production Management. Vol. 23, No. 1, 44-61 (2003)

9. Kumar, K., van Dissel, H: Sustainable Collaboration: Managing Conflict and Cooperation in Interorganizational Systems. MIS Quarterly, Vol. 20, No. 3, 279 - 300 (1996)

10. Martinez M. T., Fouletier P., Park K. H., Favrel J.: Virtual enterprise - organisation, evolution and Control. Int. J. of Product. Econom., Vol. 74, No. 1-3, 225-238 (2001)

11.Masing J.: Handbuch Qualität: Grundlagen und Elemente des Qualitätsmanagement: Systeme-Perspektiven, Carl Hanser Verlag, München (2007)

12.Molina, A.G., Bremer, C.F.: Information model to represent the core competences of virtual industry clusters. Technical Note (1997)

13.Petridis, K.D.: Qualität in der Informationsgesellschaft - Die Rolle der Qualität in virtuellen Unternehmen und E-Commerce-Strukturen. QZ - Qualität und Zuverlässigkeit (2001)

14.Prahalad, C.K., Hamel, G.: The core competence of the corporation. Harvard Business Review, Vol. 68, No. 3. 79-91 (1990)

15.Robinson, C.J., Malhotra, M.K.: Defining the concept of supply chain quality management and its relevance to academic and industrial practice. Int. J. Prod. Econ, Vol. 96, 315-337 (2005)

16.Romano, P., Vinelli, A.: Quality management in a supply chain perspective - Strategic and operative choices in a textile-apparel network. Int. J. Operations \& Production Management, Vol. 21, No.4, 446-460 (2001)

17.Seifert, M.: Collaboration Formation in Virtual Organisations by applying prospective Performance Measurement, Ph.D. Thesis, University of Bremen (2009)

18.Sitek, P., Graser, F., Seifert, M.: Partner profiling to support the initiation of collaborative networks, in Pawar, K.S., Thoben, K.-D., Pallot, M. (eds.) Concurrent Innovation: an emerging paradigm for Collaboration \& Competitiveness in the extended enterprise, Proc. $13^{\text {th }}$ International Conference on Concurrent Enterprising, Sophia-Antipolis, pp. 213-220 (2007)

19.Sitek, P., Seifert M., Thoben, K.-D.: On inter-organisational effects on the quality of products in collaborative networked enterprises. In Smeds, R. (ed.) Innovations in Networks, Proc. of APMS 2008, Helsinki University of Technology, Espoo, pp. 517-528 (2008)

20.Taylor, F.W.: Principles of Scientific Management. Scientific Management - Reprint (1947)

21.Thoben, K.-D., Jagdev, H.S.: Typological Issues in Enterprise Networks. J. Production Planning and Control, Vol.12, No.5, 421-436 (2001)

22.Thompson, J.D.: Organizations in Action, McGraw Hill, New York (1967) 